This the Accepted Manuscript of:

Marco Pignatti, Pierluigi Tos, Cristina Garusi, Fabrizio Schonauer, Mario Cherubino, Cesare Tiengo, Davide Ciclamini, Santolo Cozzolino, Eva Di Maro, Lucian P. Jiga, Mihai Ionac, Alexandru Nistor, Alexandru V. Georgescu, Valentina Pinto, Federico A. Giorgini, Giorgio De Santis, Salvatore D'Arpa,

A sequence of flaps and dissection exercises in the living model to improve the learning curve for perforator flap surgery,

Injury, Volume 51, Supplement 4, 2020, Pages S22-S30.

Final version available: https://doi.org/10.1016/j.injury.2020.02.006

Rights / License:

The terms and conditions for the reuse of this version of the manuscript are specified in the publishing policy. For all terms of use and more information see the publisher's website.

This item was downloaded from IRIS Università di Bologna (https://cris.unibo.it/)

When citing, please refer to the published version. 


\section{A sequence of flaps and dissection exercises in the living model to improve the learning curve for perforator flap surgery}

Marco Pignatti ${ }^{1}$, Pierluigi Tos ${ }^{2}$, Cristina Garusi ${ }^{3}$, Fabrizio Schonauer ${ }^{4}$, Mario Cherubino $^{5}$, Cesare Tiengo ${ }^{6}$, Davide Ciclamini ${ }^{7}$, Santolo Cozzolino $^{8}$, Eva di Maro ${ }^{9}$ Lucian P. Jiga $^{10}$, Mihai Ionac ${ }^{11}$, Alexandru Nistor ${ }^{12}$, Alexandru V. Georgescu ${ }^{13}$, Valentina Pinto $^{14}$, Federico A. Giorgini ${ }^{1 \& 15}$, Giorgio De Santis ${ }^{15}$, Salvatore D'Arpa ${ }^{16}$

1. Plastic Surgery, Sant'Orsola University Hospital. DIMES, Bologna University. Bologna. Italy

2. UOC di Microchirurgia e Chirurgia della Mano - ASST Gaetano Pini-CTO Milano, Milano, Italy

3. Dipartimento di Chirurgia Plastica e Ricostruttiva, Istituto Europeo di Oncologia, Milano, Italy

4. Chirurgia Plastica e Ricostruttiva, Università Federico II, Napoli, Italy

5. Division of Plastic and Reconstructive Surgery, Department of Biotechnology and Life Sciences (DBSV), University of Insubria, Varese, Italy.

6. Plastic and Reconstructive Surgery Unit, Padova University Hospital, Padova, Italy

7. Orthopaedic and Traumatology 2, Hand and Microsurgery Unit, A.O.U. Città della Salute e della Scienza, C.T.O. Hospital, Torino, Italy

8. Direttore UOC Formazione, Ricerca e Cooperazione Internazionale, AORN A. Cardarelli

9. Veterinario Designato UOC Formazione, ricerca e cooperazione Internazionale, AORN A. Cardarelli

10. Department for Plastic, Aesthetic, Reconstructive and Hand Surgery

Evangelisches Krankenhaus, Medical Campus - University of Oldenburg. Germany.

11. Victor Babes University of Medicine and Pharmacy, Division of Reconstructive Microsurgery, Timisoara, Romania

12. Pius Brazneu Center. Victor Babes University of Medicine and Pharmacy, Division of Reconstructive Microsurgery, Timisoara, Romania

13. Plastic Surgery and Reconstructive Microsurgery. University of Medicine Iuliu Hațieganu. Spitalul Clinic de Recuperare Cluj Napoca, ROMÂNIA.

14. Plastic Surgery, Sant'Orsola University Hospital. Bologna. Italy

15. Chirurgia Plastica, Università di Modena e Reggio, Policlinico di Modena, Italy;

16. Plastica and Reconstructive Surgery, Department of Surgical, Oncological and Oral Sciences (DICHIRONS), University of Palermo. Via del Vespro 129. 90127 Palermo, Italy.Email: salvatore.darpa@unipa.it 


\begin{abstract}
Introduction: The training to learn how to perform perforator flaps requires practice on a living model to optimize dissection and to evaluate outcome. The purpose of this study was to describe a training model that optimizes the use of animals in order to perform the maximum number of exercises per animal.

Material and methods: The sequence has been planned and practiced by the first and last author, recorded perfected and implemented in a two-day surgical course. The sequence was then evaluated by the trainers and the trainees by means of a questionnaire.

Results: All students were able to complete the sequence of exercises before the end of the second day except two (8/10) who could not complete one exercise each. The students considered the Deep Superior Epigastric Artery Perforator flap the most difficult to perform, being the most technically demanding. The sequence of exercises was judged either easily reproducible or reproducible by all the students. Two students suggested to postpone the DSEAP flap to the second day, after some training, to optimize the experience with the most challenging and rewarding flap. Conclusions: The training sequence proposed offers a wide range of exercises and allows four trainees, divided in two teams, to work and learn on the same animal. They can perform a wide range of flaps and also harvest the internal mammary vessels. The living model allows for evaluation of the quality of the surgical performance, judged by the difficulties and complications encountered during dissection, and finally through the feedback of flap perfusion.
\end{abstract}




\section{INTRODUCTION}

The use of living animal models for training is well established in several subspecialties of surgery. Small animal models (rat, rabbit) are commonly used in microsurgery: from vessel preparation, to microsurgical anastomosis, to complete flap or organ transfer ${ }^{\mathbf{1 - 5}}$ Although necessary to acquire the basic microsurgical techniques, these models do not allow to reproduce anatomical and surgical conditions similar to the ones found in humans, especially regarding perforator flap surgery. Cadaver courses are used for this purpose, but they are not ideal, because non-living tissues do not bleed nor respond to surgical manipulation. Furthermore, the pliability and quality of dead tissues rarely resembles a normal surgical setting. Finally, flap viability cannot be verified, and thus there is no feedback on the quality of dissection obtained. ${ }^{6}$ The porcine model seems to compensate for the described drawbacks of other surgical models. ${ }^{\mathbf{7 , 8}}$

Some groups of surgeons around the world have acquired this kind of experience, but only a few papers in the literature describe surgical exercises performed in pigs $\mathbf{7 , 8 , 9 , 1 0 , 1 1}$. Starting in 2012, a group of plastic surgeons from Timisoara in Romania were among the first to organize and promote a perforator flap course on pigs for international students (Pius Brazneu Center. Victor Babes University, Timisoara. Romania). Inspired by their experience, the Italian Microsurgical Society (SIM) has organized in-house training courses for perforator flaps in living tissues.

The purpose of this article is to describe a sequence of perforator flaps and dissection exercises that can be performed in pigs. This sequence includes existent techniques and new ones that reproduce clinical situations in humans. The purpose of the sequence is to optimize the use of the animal during a short course in order to 
minimize the number of animals used, whilst maximizing their exploitation (respecting the 3R principle: reduction, refinement, and replacement); to describe the anatomy of flaps that have not yet been described in the literature; and to verify the feasibility and efficacy of this sequence by students inexperienced in perforator flap surgery.

\section{MATERIALS and METHODS}

\section{Animals}

The surgical exercises were performed on female swine (Sus scrofa domesticus, ssp. large white; $40 \mathrm{~kg}$ ). The animals were included in an experimental protocol (protocol no 38.2010.01.001), which received complete approval from both the local Ethical Committees on Animal Experimentation.

In accordance with the Italian law (DL n 26 del $4^{\text {th }}$ of march 2014) the " $3 \mathrm{R}$ rules" were respected: REPLACEMENT: as said, is not possible to perform this kind of experiment on a dead body primarily because bleeding is needed to recognize a properly performed surgery and adequate tissues manipulation. For this purpose the animal model closer to the human model was chosen and, within this category, the animal with the lowest grade of evolution. REDUCTION: the lowest possible number of subjects was used. . REFINEMENT: all the procedures were performed under the veterinarian's (expert in animal laboratory) supervision, to minimize the animal discomfort and pain. All the pigs were located in specific boxes with free access to food and water. The general anesthesia in accord with the Italian law followed the following protocol: premedication with intramuscular injection of Zoletil 50/50 (0,5 $\mathrm{ml} / \mathrm{kg})$, induction with Propofol EV $(6 \mathrm{mg} / \mathrm{kg})+$ Ketamine intravenously $(10 \mathrm{mg} / \mathrm{kg})$, maintenance with sevorane $2 \%$ by air + Rocuronio EV (0,2 mg/kg )+ Propofol 
infusion if needed. Analgesia was obtained with Butorfanolo intravenously (0,1-0,4 $\mathrm{mg} / \mathrm{kg}$ ). Orothracheal intubation, ventilation with an anesthetic machine and multiparametric monitoring were used. In accordance with the law at the end of the surgery all animals were euthanized with an intravenous injection of a lethal dose of $\operatorname{Tanax}(1 \mathrm{ml} / 3 \mathrm{~kg})$

Equipment Surgical procedures were performed under 3.5x or $4.5 \mathrm{x}$ expanded field binocular loupe magnification (Designs for Vision, Ronkonkoma, NY, USA ). The procedures were recorded with a GoPro camera (GoPro Inc. USA) and simultaneously with a head mounted, 4x magnification, Loupecam system (LoupeCam ${ }^{\circledR}$ by VizVOCUS Inc. ， Scottsdale, AZ, USA). Photos were taken using two SLR cameras (Canon Inc. Japan) during surgery at relevant time points.

Procedures Dissections were performed by two senior plastic surgeons (first and last authors) specialized in microsurgery and perforator flap surgery. One further assistant helped on the surgical field, two others acquired the images and video material. The sequence of exercises was then repeated by 10 students Table 1.

Once taken into account the anatomical differences between the human and the porcine model with some variations in the flap planning and marking, the dissection of tissues resembles very much the human situation. The surgical experience that can be obtained in a perforator flap course in the porcine model can therefore be of great help for the surgeon to transfer his/her knowledge to the human setting

To obtain the best experience in the unit of time during a training course for the highest number of trainees, two students operated at the same time on two different flaps in two different anatomical areas on the same side of the animal. 
Table 2 At the end of the course, the questionnaire in Table 3 was administered to all the students .

\section{Flaps Performed}

We report below details on the flaps performed, underlining the anatomical differences between pigs and humans.

Deep Superior Epigastric Artery Perforator (DSEAP) flap

The DSEAP flap allows to closely reproduce all the steps of DIEAP flap harvesting. While the main vessel that nourishes the human DIEAP flap originates caudally (deep inferior epigastric artery), in pigs the main vessel originates cranially, (deep superior epigastric artery) and the swine flap is therefore called DSEAP. ${ }^{\mathbf{7} 9}$

As previously described, in pigs a superficial muscular layer substitutes the subcutaneous tissue of humans, the muscular fascia is thinner, as is the rectus abdominis muscle. The vascular (perforators lined in two rows) and nervous (rectus motor branches) local anatomy, essential for the surgical training, is very similar in pigs and humans ${ }^{\mathbf{1 0}}$ The intramuscular dissection of other minor perforators of the two rows can be carried out to increase the surgical practice.

During the surgical phases of the dissection, it is also possible to prepare a superficial vein, like it should be done in humans, for additional venous drainage in case of congestion.

$\underline{\text { Lateral InterCostal Artery Perforator (LICAP) flap and Internal Mammary Artery }}$ Perforator (IMAP) flap

The dissection of the LICAP flap (Figure 1) and IMAP flap (Figure 2) is particularly useful for the training of freestyle pedicled perforator flaps. The approximate position of the perforator, known on the basis of anatomy, is verified and 
more precisely defined through surgical exploration. The student can practice in a situation similar to the one that it will be found in the clinical setting and also learn, or improve, to change plan, lap position or shape according to the real position of the perforator.

\section{$\underline{\text { Internal Mammary Vessels (IMVs) }}$}

In autologous breast reconstruction, where perforator flaps are frequently used, the recipient vessels may be the IMVs or the thoracodorsals.

The IMVs are considered the first choice by most of the plastic surgeons.

The internal mammary artery and vein (or veins) may be reached either removing one costal cartilage (trans-chondral technique) or removing the muscles in one intercostal space (rib-sparing or intercostal technique). The former, traditionally used since its first description ${ }^{12,13}$ has been described also in the swine model ${ }^{11}$

Although the trans-chondral approach has been described in pigs, we decided to develop a new model for the training of the trans-muscular dissection technique (Figure 3), the one regularly used in humans, during microsurgical breast reconstruction that is considered to be safer. ${ }^{\mathbf{1 4}}$ This approach closely resembles the human situation and is therefore particularly useful to train the young surgeons to avoid or manage bleeding and pleural perforation. Anatomical differences in pigs are a more prominent anterior thoracic wall, a wider space between the thoracic wall and the vessels, where adipose tissue is less represented, larger veins with more resistant walls to surgical trauma.

\section{$\underline{\text { Transverse Miocutaneous Gracilis flap (TMG) }}$}

The TMG flap has gained popularity in clinical practice as a viable option for autologous breast reconstruction ${ }^{15}$ Although not definable as a perforator flap, the transverse miocutaneous gracilis (TMG), also called transverse upper gracilis (TUG), 
is included in this sequence of flaps because of its usefulness in the flap dissection learning and because of its popularity as an alternative option to the perforator flaps DIEP and SGAP for breast reconstruction in humans. It is probably the flap most frequently described in the porcine model in the literature. ${ }^{7}$

\section{Thoracodorsal Artery Perforator (TDAP) flap}

As a modern and elegant evolution of the workhorse Latissimus Dorsi flap, the

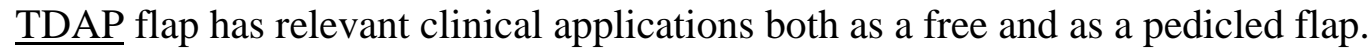

Offering this new training model is therefore useful.. (Figure 4), The anatomy is very similar to the human one and the technique used for dissection is essentially "free style". The exploratory incision is obviously based on the anatomical landmarks of the posterior axillary pillar and the expected position of the thoracodorsal vessels, but the real position of the most adequate perforator (for size and position) needs to be discovered in each case. Another useful phase of the dissection of this flap is the separation of the TD artery and vein from the TD nerve.

\section{Superior Gluteal Artery Perforator (SGAP) flap}

The surgical training for the SGAP flap in humans can be effectively obtained in pigs (Figure 5). The porcine SGAP flap model, despite a few anatomical differences in muscle orientation, has, compared to humans, similar size of the vessels and a similarly challenging dissection under the muscle where several side branches need to be clipped to elongate the flap pedicle. A detailed description of the surgical technique has been reported. ${ }^{7,16,17,18}$

\section{Dorsal Cervical Artery Perforator (DCAP) flap}

The DCAP is a very useful flap for the training of septal perforators dissection. (Figure 6). The flap is located in the anatomical area that in humans allows the elevation of free-style pedicled flaps over the trapezius muscle or based on 
the paravertebral perforators. The dissection technique is, on the other hand, septal and not intramuscular. This is easy to perform and, due to the virtual space of loose areolar tissue in between septa, it is a clean and rewarding dissection for the trainee. The vessel can be followed for a few centimeters under the surrounding skeletal muscles.

\section{Results}

The identification and dissection of perforating vessels appeared to be very similar to that in humans in all of the flap models. This was true both for the intramuscular perforators and for the septal perforators. In the sequence-development phase, performed by experienced microsurgeons, all seven flap models showed adequate perforating vessels, the one largest or better positioned (especially for the pedicled free-style flaps) was eventually chosen and dissected down to the main vessel. All flaps were perfused at the end of the dissection and the intramuscular vessels were safely isolated with the two different techniques available. We performed a total of nine surgical exercises, five of which, to our knowledge, not yet described in the literature (TDAP, IMVs transmuscular, IMAP, LICAP, DCAP).

When reproduced by each student during the training course, the sequence proposed was correctly followed and judged feasible, although some dissections were not successful (either due to arterial ischemia or to venous stasis of the flap, or because the trainee was not able to complete the task despite the supervision of the tutors). At the end of the dissection a total of four flaps suffered from arterial ischemia (1 DSEAP, 2 TDAP, 1 SGAP) and a total of five flaps developed venous congestion (2 DSEAP, 1 TDAP, 1 SGAP, 1 LICAP) 
All students were able to complete the sequence of exercises before the end of the second day except two (8/10) who could not complete one exercise (for rupture and bleeding of main vessel in one case and for inadequate perforators in the other) The students considered DSEAP the flap most difficult to perform because it was the most technically demanding. The sequence of exercises was judged either easily reproducible or reproducible by all the students. Two students suggested to postpone the DSEAP flap to the second day, after some training, to optimize the experience with the most challenging and rewarding flap.

\section{Discussion}

The purpose of our study was to teach a group of students how to perform in a pig model a sequence of perforator flaps and dissection exercises. The exercises spanned from muscle perforators and septal perforator flaps to musculocutaneous flaps, including the isolation of IMVs

This series of new and known flaps and dissection exercises allows to optimize the resources. The animal is operated in almost all anatomical areas. To optimize the training experience, different kinds of perforator flaps are included, therefore requiring dissection of intramuscular perforators and septal perforators, but also allowing the students to practice the mental training and surgical technique to plan and perform free-style perforator flaps. These flaps can be used free or for local soft tissues reconstructions. In the latter case, thay can reach the defect with different kind of movements, including 90 to 180 degrees rotation as propeller flaps ${ }^{19}$ (Figure 7)

This sequence included previously described techniques (DSEAP flap, transchondral IM vessels preparation, TMG, SGAP flap ) and new ones (TDAP, 
IMVs transmuscular, IMAP, LICAP, DCAP) that reproduce clinical situations in humans. We showed that it is possible to perform all these nine exercises on one side of one animal, therefore minimizing the use of animals. Having two teams working simultaneously also allowed time optimization. Although other models used for training can be used, they should be considered as complementary or preparatory to the living tissue models.

In particular, studying the surgical anatomy in cadavers while elevating perforator flaps is essential to feel at ease with the normal structures and to learn distances, size and orientation of tissues. Practicing surgery and microsurgery on the small animal model refines the surgical movements, improves precision and emphasizes the respect for delicate tissues. Practicing sophisticated surgery, like elevation of perforator flaps, on living tissues of larger animals is the third step of a complete surgical training for modern microsurgeons. In fact, despite the small anatomical differences (mainly in skeletal muscle orientation and panniculus carnosus instead of subcutaneous fat), most of the difficulties and dangers encountered in perforator flap surgery in humans, related to active blood stream in living tissues, are found in pigs.

\section{CONCLUSIONS}

This series of exercises on new and known flaps and vessels dissection in the pig, in conditions similar to humans, allows training on intramuscular perforators, on septal perforators, on free-style flaps both for local (also as propeller perforator flaps) and microsurgical reconstructions, and on recipient vessels preparation. The sequence increases the number of flaps performed and optimizes the resources by using the animal extensively. 


\section{REFERENCES}

1. Pignatti M, Benati D, Cavadas PC.Effect of the two-wall-stitch mistake upon patency of rat femoral vein anastomosis: Preliminary observations. Microsurgery. 2004; 24(4):339-44.

2. Amoroso M, Özkan Ö, Özkan Ö, Başsorgun Cİ, Ögan Ö, Ünal K et al.The Effect of Normovolemic and Hypervolemic Hemodilution on a Microsurgical Model: Experimental Study in Rats. Plastic and Reconstructive Surgery. 2015; 136(3):512-9.

3. Tee R, Morrison WA, Dilley RJ.A novel microsurgical rodent model for the transplantation of engineered cardiac muscle flap. Microsurgery. 2018; $38(5): 544-52$

4. Krag C, Holck S. Microvascular anastomoses: a comparison of the end-to-end and the telescoped techniques in rats.J Microsurgery. 1980; 2(1):3-10.

5. Miyamoto S, Takushima A, Okazaki M, Ohura N, Momosawa A, Harii K. Comparative study of different combinations of microvascular anastomosis types in a rat vasospasm model: versatility of end-to-side venous anastomosis in free tissue transfer for extremity reconstruction. The Journal of Trauma: Injury, Infection, and Critical Care. 2009; 66(3):831-4.

6. Stefanidis D, Yonce TC, Green JM, Coker AP.Cadavers versus pigs: which are better for procedural training of surgery residents outside the OR? Surgery. $2013 ; 154(1): 34-7$

7. Bodin F, Diana M, Koutsomanis A, Robert E, Marescaux J, Bruant-Rodier C. Porcine model for free-flap breast reconstruction training. Journal of Plastic, Reconstructive \& Aesthetic Surgery. 2015; 68(10):1402-9 
8. Villamaria CY, Rasmussen TE, Spencer JR, Patel S, Davis MR.

Microvascular porcine model for the optimization of vascularized composite tissue transplantation. Journal of Surgical Research. 2012; 178(1):452-9

9. Minqiang X, Jie L, Dali M, Lanhua M. Transmidline abdominal skin flap model in pig: refinements and advancements. Journal of Reconstructive Microsurgery. 2012; 28(2):111-8.

10. Roggio T, Pignatti M, Cajozzo M, Tos P, De Santis G, Garusi C et al. Porcine Model for Deep Superior Epigastric Artery Perforator Flap Harvesting: Anatomy and Technique. Plastic and Reconstructive Surgery Global Open. 2018; 6(2):e1659

11. Nistor A, Ionac M, Spano A, Georgescu A, Hoinoiu B, Jiga LP.Mastering the approach of internal mammary vessels: a new training model in pigs. Plastic and Reconstructive Surgery. 2013;131(5):859e-61e.

12. Ninković M, Anderl H, Hefel L, Schwabegger A, Wechselberger G. Internal mammary vessels: a reliable recipient system for free flaps in breast reconstruction. British Journal of Plastic Surgery. 1995; 48(8):533-539.

13. Arnez ZM, Valdatta L, Tyler MP, Planinsek F.Anatomy of the internal mammary veins and their use in free TRAM flap breast reconstruction. British Journal of Plastic Surgery. 1995; 48(8):540-5.

14. Rosich-Medina A, Bouloumpasis S, Di Candia M, Malata CM. Total "rib"preservation technique of internal mammary vessel exposure for free flap breast reconstruction: A 5-year prospective cohort study and instructional video. Annals of Medicine \& Surgery. 2015; 4(3):293-300.

15. Russe E, Kholosy H, Weitgasser L, Brandstetter M, Traintinger H, Neureiter J et al.Autologous fat grafting for enhancement of breast reconstruction with a 
transverse myocutaneous gracilis flap: A cohort study. Journal of Plastic, Reconstructive \& Aesthetic Surgery. 2018; 71(11):1557-62.

16. Allen RJ, Tucker C Jr. Superior gluteal artery perforator free flap for breast reconstruction. Plastic and Reconstructive.Surgery. 1995; 95: 1207-1212

17. Blondeel PN. The sensate free superior gluteal artery perforator (S-GAP) flap: a valuable alternative in autologous breast reconstruction. British Journal of Plastic Surgery. 1999; 52:185-193

18. Gagnon AR, Blondeel PN. Superior Gluteal Artery Perforator Flap. Seminars in Plastic Surgery 2006; 20(2):79-88.

19. Pignatti M1, Ogawa R, Hallock GG, Mateev M, Georgescu AV, Balakrishnan G, Ono S, Cubison TC, D'Arpa S, Koshima I, Hyakusoku H. The "Tokyo" consensus on propeller flaps. Plastic and Reconstructive Surgery. 2011;127(2):716-22. 


\section{A sequence of flaps and dissection exercises in the living model to improve the learning curve for perforator flap surgery}

Marco Pignatti ${ }^{1}$, Pierluigi Tos ${ }^{2}$, Cristina Garusi ${ }^{3}$, Fabrizio Schonauer ${ }^{4}$, Mario Cherubino $^{5}$, Cesare Tiengo ${ }^{6}$, Davide Ciclamini ${ }^{7}$, Santolo Cozzolino ${ }^{8}$, Eva di Maro $^{9}$ Lucian P. Jiga $^{10}$, Mihai Jonac ${ }^{11}$, Alexandru Nistor ${ }^{12}$, Alexandru Georgescu ${ }^{13}$, Valentina Pinto ${ }^{14}$ Federico Giorgini ${ }^{1 \& 15}$, Giorgio De Santis ${ }^{15}$, Salvatore D’Arpa ${ }^{16}$

None of the authors has any conflict of interest to declare 


\section{Highlights}

1. Perforator flap surgery can be successfully taught in living tissues, whose quality is optimal and difficulties are similar to the ones in humans

2. We describe a sequence of perforator flaps and dissection exercises that can be performed in pigs

3. This sequence includes previously described techniques and new ones that reproduce clinical situations in humans.

4. The sequence can be successfully performed, during a course, by students not trained in perforator flap surgery 
Table 1. Course organization

SIM courses for perforator flaps in living tissues

- 5 pigs each day

- 2 surgical teams (1student, 1 assistant each), 1 tutor per animal

- The surgical teams alternate in the sequence and work simultaneously in different anatomical areas to optimize time. 
Table 2. Flap sequence. See text for abbreviations.

A total of 9 different exercises are performed. Exercises 1 and 2 have a + sign meaning that the exercise named "IMAP \& IMvs" includes

a. the dissection of the IMAP flap,

b. the preparation of the IM vessels with the traditional transchondral technique,

c. the preparation of the IM vessels with the safer trans-intercostal muscle technique

\begin{tabular}{lll}
\hline Supine position & Team $\mathbf{1}$ & Team $\mathbf{2}$ \\
\hline $\mathbf{1 +}$ & DSEAP & IMAP \& IMvs \\
$\mathbf{2 +}$ & IMAP \& IMvs & DSEAP \\
$\mathbf{3}$ & LICAP & TMG \\
$\mathbf{4}$ & TMG & LICAP \\
Left Lateral decubitus & & \\
$\mathbf{5}$ & TDAP & SGAP \\
$\mathbf{6 a}$ & DCAP & \\
$\mathbf{R i g h t}$ Lateral decubitus & & \\
$\mathbf{6 b}$ & & DCAP \\
$\mathbf{7}$ & SGAP & TDAP \\
\hline
\end{tabular}

\section{LEGEND to TABLE 2}

Supine pig.

Exercise 1: student 1 performs right DSEAP, student 2 dissects IMAP and then prepares left IMvs with two techniques.

Then they swap

Exercise 2: student 1 dissects IMAP and then prepares left IMvs with two techniques, student 2 performs left DSEAP

Exercise 3: student 1 performs right LICAP, student 2 prepares left TMG

Then they swap

Exercise 4: student 1 performs right TMG, student 2 prepares left LICAP

Left decubitus

Exercise 5: student 1 performs right TDAP student 2 prepares right SGAP

Exercise 6/a: student 1 or 2 (the first finishing the previous exercise) performs right DCAP.

Right decubitus

Exercise 6/b: student 1 or 2 (the remaining one) performs left DCAP

Exercise 7: student 1 performs left SGAP, student 2 prepares left TDAP

The raising of TDAP and SGAP flaps is optimally performed with the pig in lateral decubitus. However it is possible to perform the exercises on the animal in prone position. In this case time will be saved both avoiding the turning of the pig and allowing constant contemporary dissections. The sequence, in this case of prone position, will be the following.

Exercise 5: student 1 performs right TDAP (Toracodorsal Artery Perforator), student 2 prepares left SGAP (Superior Gluteal Artery Perforator).

Exercise 6: student 1 performs right DCAP (dorsocervicalis artery perforator) . student 2 prepares left TDAP (Toracodorsal Artery Perforator), 
Exercise 7: student 1 performs right SGAP, student 2 prepares left DCAP (dorsocervicalis artery perforator) 


\section{Table 3 STUDENTS' QUESTIONNAIRE}

\begin{tabular}{|c|c|}
\hline 1 & $\begin{array}{l}\text { Where you able to complete the sequence of exercises before the end of the second } \\
\text { day? } \\
\text { Sei riuscito a completare la sequenza di esercizi entro la fine del secondo giorno? }\end{array}$ \\
\hline 2 & $\begin{array}{l}\text { How many exercises did you complete? } \\
\text { Quanti esercizi sei riuscito a completare? }\end{array}$ \\
\hline 3 & $\begin{array}{l}\text { How many exercises you were't able to complete? } \\
\text { Quanti non sei riuscito a completarne? }\end{array}$ \\
\hline 4 & $\begin{array}{l}\text { Which exercise did you find the most difficult? Why? } \\
\text { Quale hai trovato più difficile? E perche? }\end{array}$ \\
\hline 5 & $\begin{array}{l}\text { How many flaps, at the end of the dissection, had an arterial ischemia (pale flap)? } \\
\text { Quanti lembi alla fine della dissezione avevano un problema di ischemia arteriosa (lembo pallido)? }\end{array}$ \\
\hline 6 & $\begin{array}{l}\text { How many flaps, at the end of the dissection, had a venous stasis (congested flap)? } \\
\text { Quanti lembi alla fine della dissezione avevano un problema di stasi venosa (lembo viola)? }\end{array}$ \\
\hline 7 & $\begin{array}{l}\text { How would you judge the sequence of exercises (not the difficulty of the dissection, } \\
\text { but the order and sequenceof the exercises to be done) } \\
\text { - Easily riproducible } \\
\text { - Riproducible } \\
\text { - Imposs to complete } \\
\text { Come giudicheresti la sequenza degli esercizi (non la difficoltà delle dissezioni ma l'ordine e la successione degli } \\
\text { esercizi da realizzare)? } \\
: \text { Facilmente riproducibile } \\
\text { - Riproducibile } \\
\text { Impossibile da realizzare }\end{array}$ \\
\hline 8 & $\begin{array}{l}\text { Suggestions and other comments } \\
\text { Suggerimenti e altri commenti }\end{array}$ \\
\hline
\end{tabular}




\section{Legends}

Figure 1. LICAP flap.

A. The preoperative markings draw around the hand-held doppler signal

B. One margin of the flap is incised and dissection proceeds preserving all perforators of adequate caliber.

C. The best perforator is selected and followed splitting the muscle fibers

D. Until a vessel of adequate size or a long-enough pedicle is obtained

Figure 2. IMAP flap.

A. The preoperative markings draw over the parasternal spaces and in lateral direction. Incision of the lateral margins

B. Dissection performed from lateral to medial preserving all perforators of adequate caliber.

C. The best perforator is selected and followed splitting the muscle fibers

D. The flap at the end of dissection, showing a well perfused color

Figure 3. IM vessels preparation.

A. Incision of skin and muscle parallel to the intercostal space, lateral to the sternal margin. This incision is part of one margin of the IMAP flap (in our sequence of surgical exercises). Keeping the incision divaricated with a autostatic retractor (Weitlaner), the costal plane is exposed together with the intercostal muscles.

B. C. D: rib-sparing or intercostal technique

B. The intercostal muscle is dissected out of the space starting a few centimeters lateral to the sternal margin and proceeding medially

C. Under the muscle, a bluish color is seen due to the cavity and the presence of the Internal Mammary vessels 
D. The vessels (one artery and one vein in this case) have been isolated from the surrounding tissues and from eachother. The collateral branches have been closed and divided

E. The vessels are visible, a background is positioned and the clips and ligatures of the collateral branches can be noted.

F. The intercostal space is, in this different dissection, quite small and would add difficulties to the microvascular anastomosis that will be here performed with any flap (DIEP/DSEAP in most of the cases). To widen the space to be able to perform the anastomosis in a safer way, the cranial half of the cartilage of the rib caudal to the space (or the entire rib cartilage) can be removed

G. Removal of the costal cartilage with a Luer to improve vision and control of the IM vessels

Figure 4. TDAP flap.

A. The preoperative markings draw over Latissimus Dorsi muscle. The planned skin island in blue, the usual location of the muscle fibers in red

B. Incision of the anterior tip of the skin island with cranial a caudal margins for a few centimeters to allow dissection and proper visualization of perforators.

C. A perforator of adequate caliber is found and the slitting of muscle fibers around it is performed.

D. The perforator is followed through the latissimus dorsi muscle and under it

E. Further dissectio and clipping of the side branches. A background has 
been positioned to show the vessels better

F. The flap was well perfused and it has been detached to be then reanastomosed elsewhere.

Figure 5. SGAP flap.

A. The preoperative markings draw over the gluteal area according to the literature (ref 7). The great throcanter and the Anterior Superior Iliac Spine guide the planning

B. After the usual sequeance of incision of one margin, selection of the best perforator and splitting of the muscle (not shown), the perforator is followed through the gluteus muscle and under it

C. Further dissection is necessary to elongate the pedicle (like in humans)

D. Main vessels are reached under the muscle and patient clipping of the side branches allows to increase size and lenght of the pedicle.

E. A background has been positioned to show the vessels better

F. The flap is well perfused based on the single perforator, clearly visible here.

Figure 6. DCAP flap.

A. The preoperative markings draw over the cervical area. An ellipse with one margin on the midline and the other margin on the left of the dorsum in this case is visible. Another anatomical landmark is the tip of the scapula

B. The lateral margin has been incised (skin and panniculus carnosum), and a loose areolar plane is encountered where vessels entering the skin island, coming from deep are seen.

C. One septal perforator is chosen and followed in the septum, without 
muscle splitting, going lateral and deep under the muscle.

D. Further dissection is necessary to elongate the pedicle

E. A background has been positioned to show the vessels better

F. The flap is detached

Figure 7. Propeller movement

These flaps can be used free or for local soft tissues reconstructions, as propeller flaps. A LICAP flap has been dissected on a single perforator, followed and freed for several centimeters. The sequence shows the clockwise propeller movement of 180 degrees, without compromizing the flap perfusion 


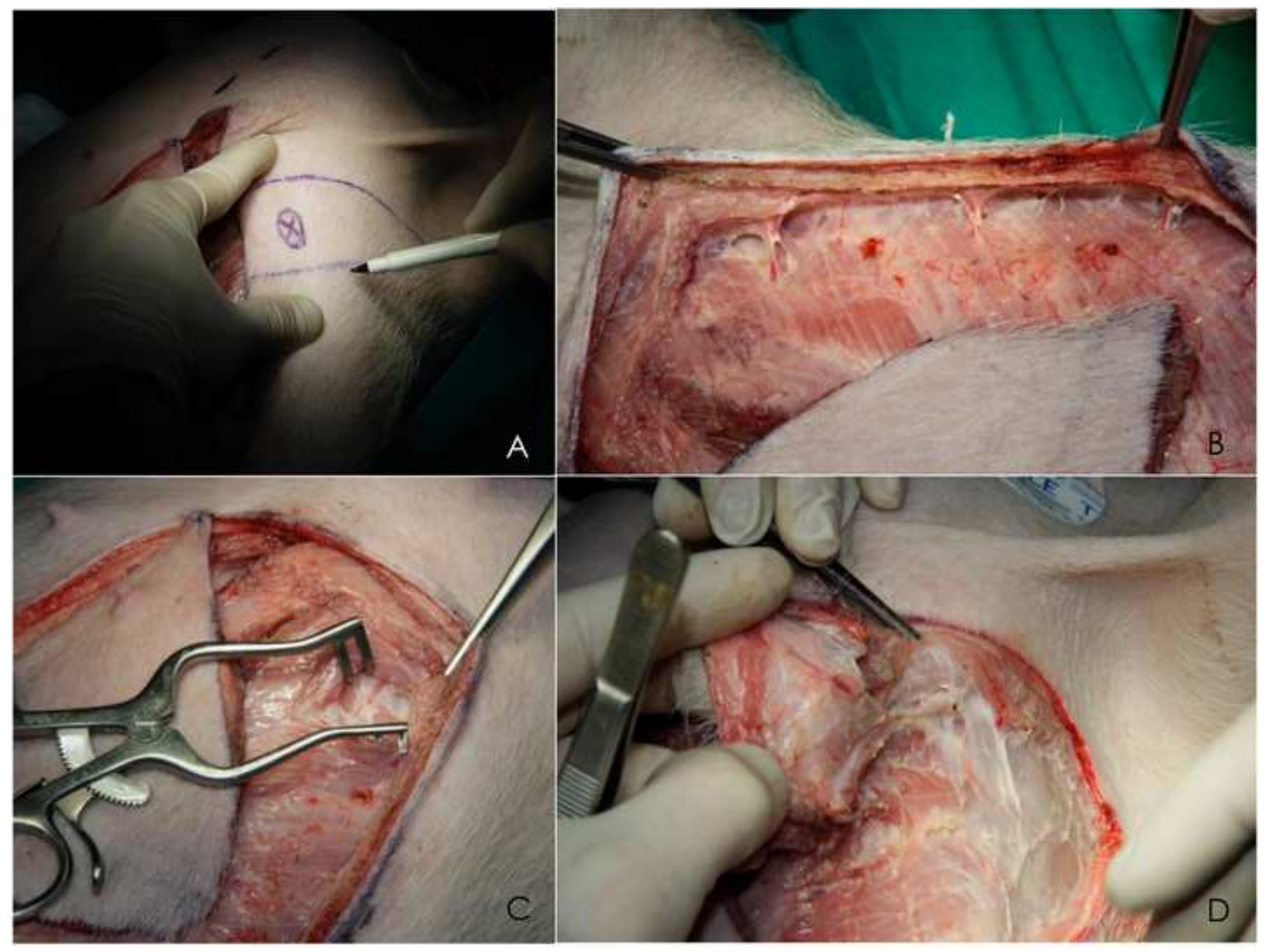




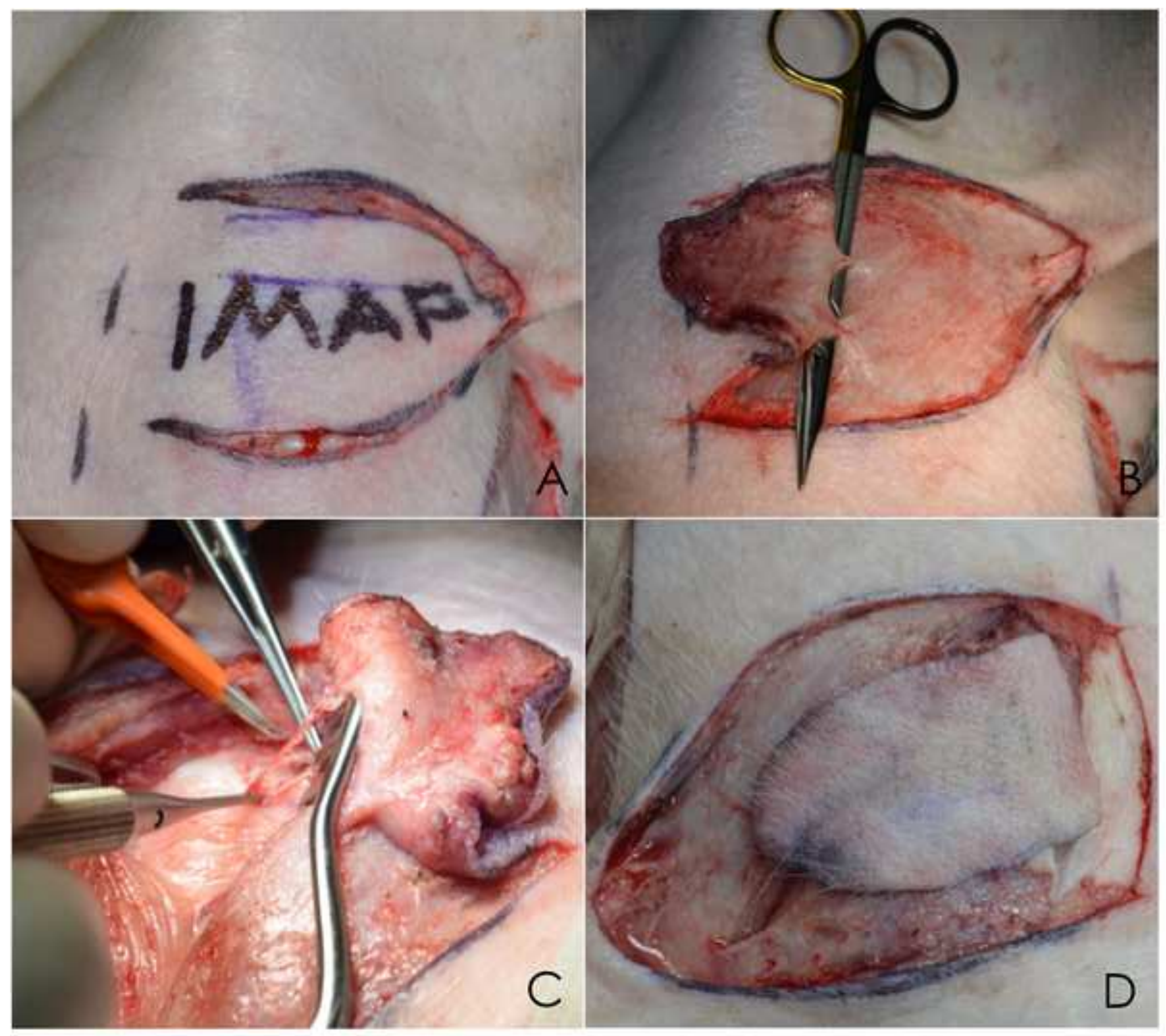




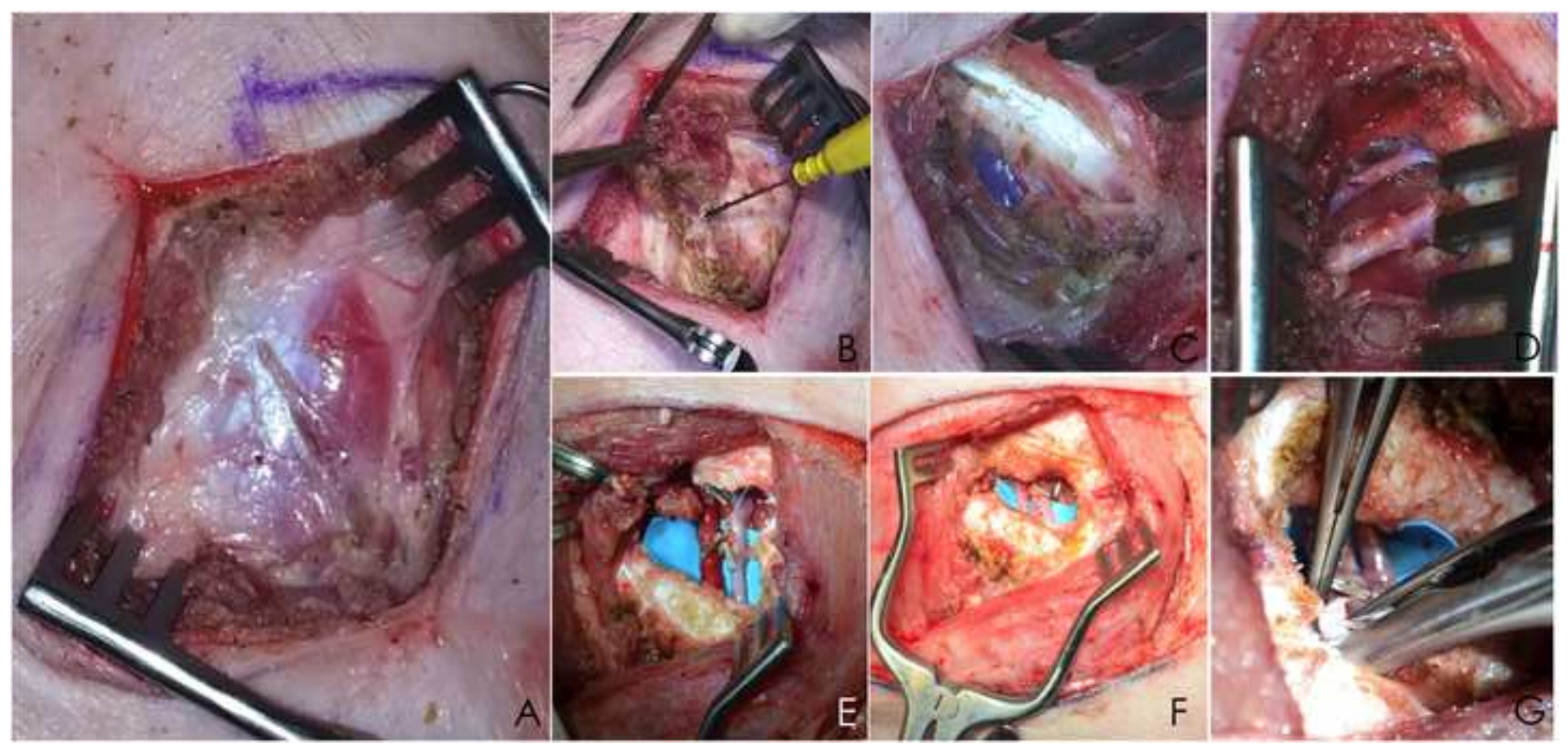




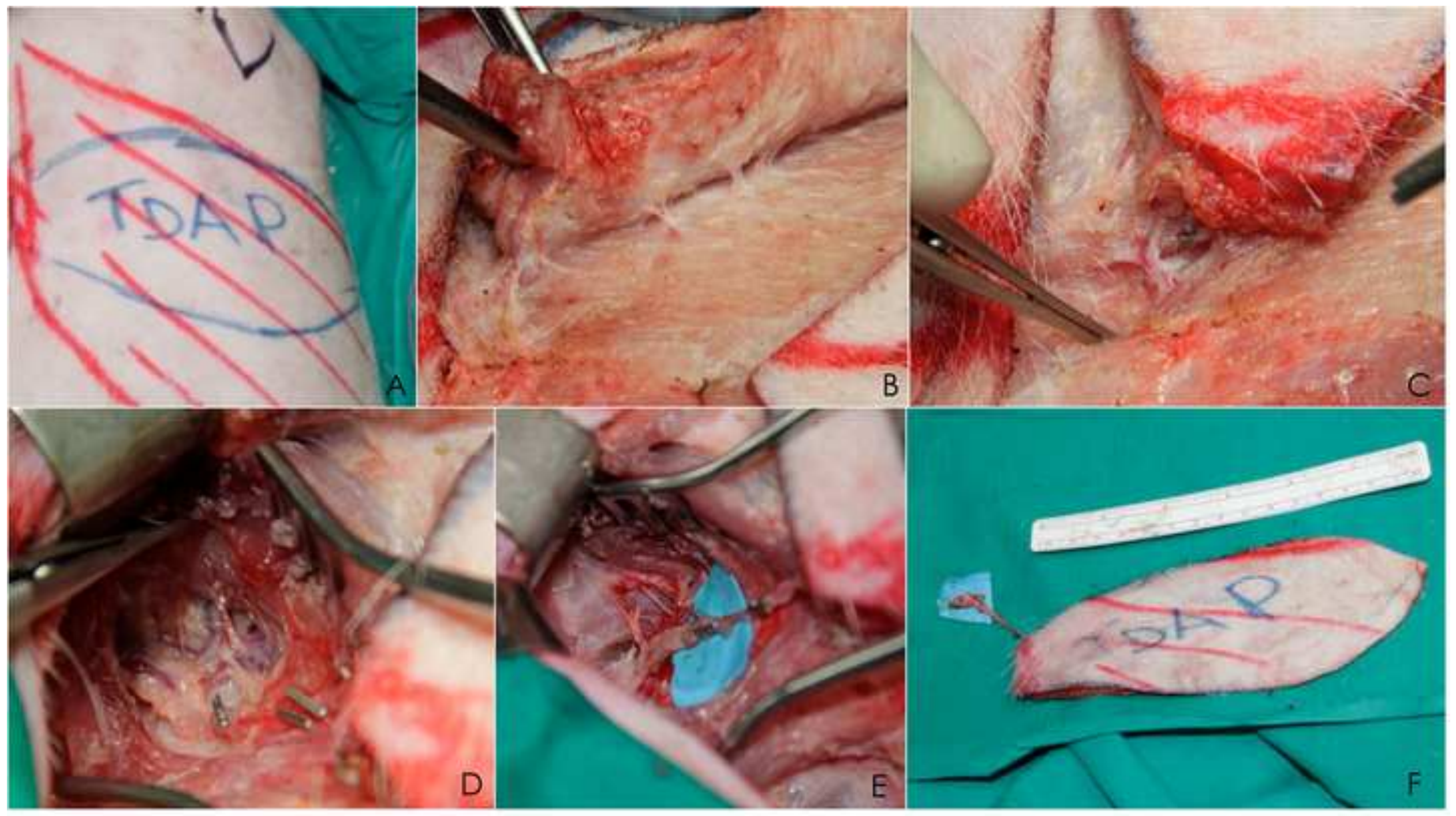




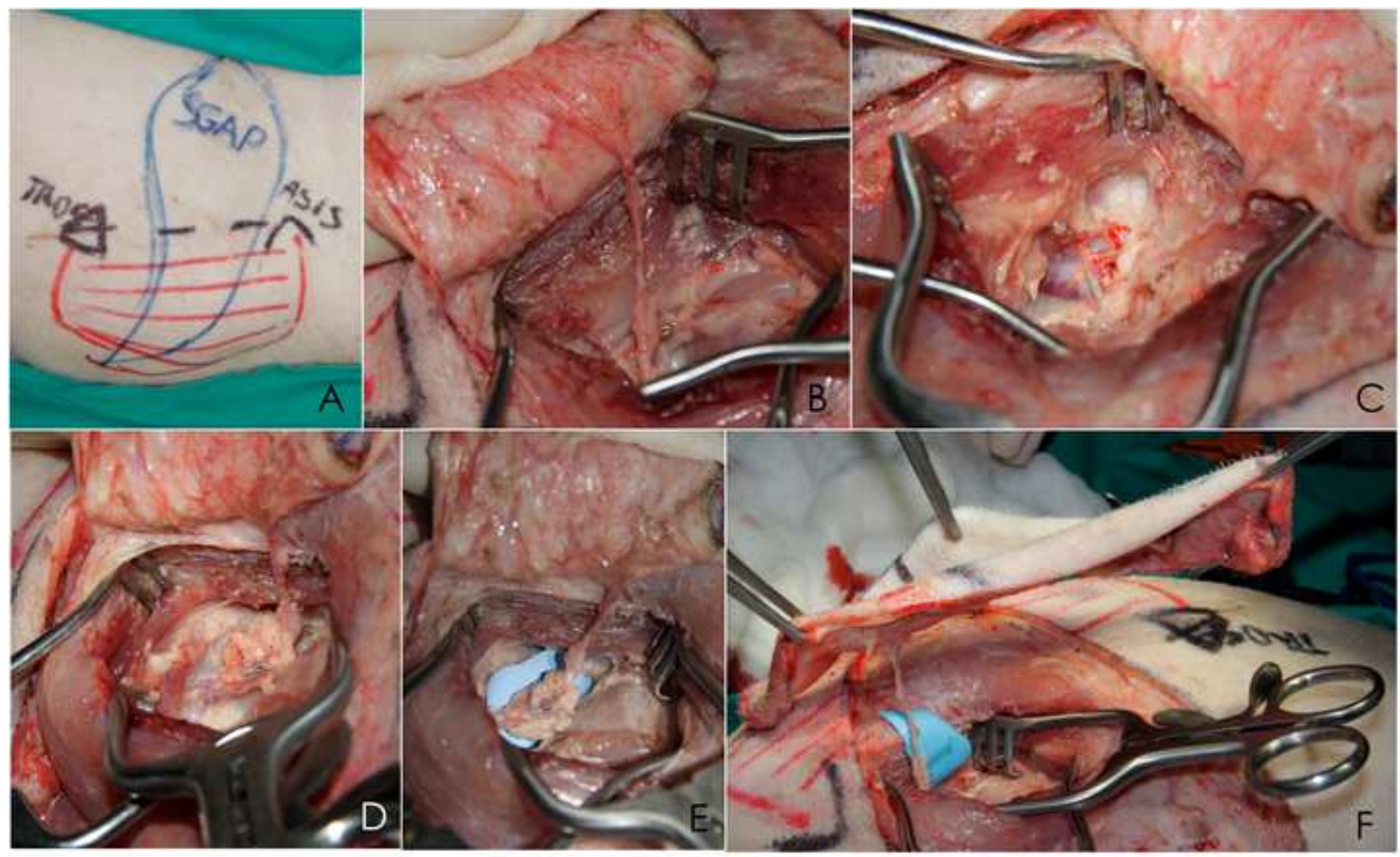




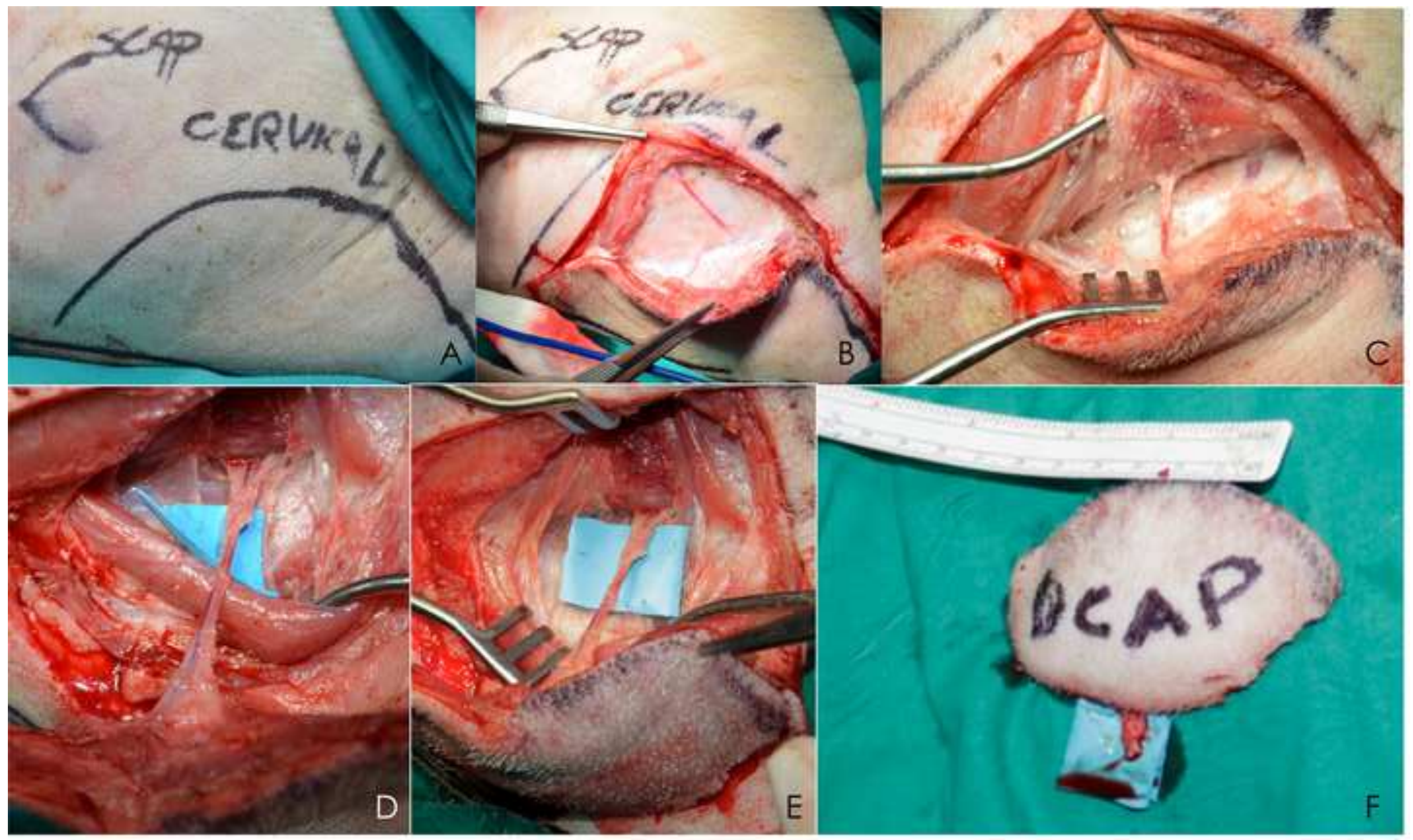




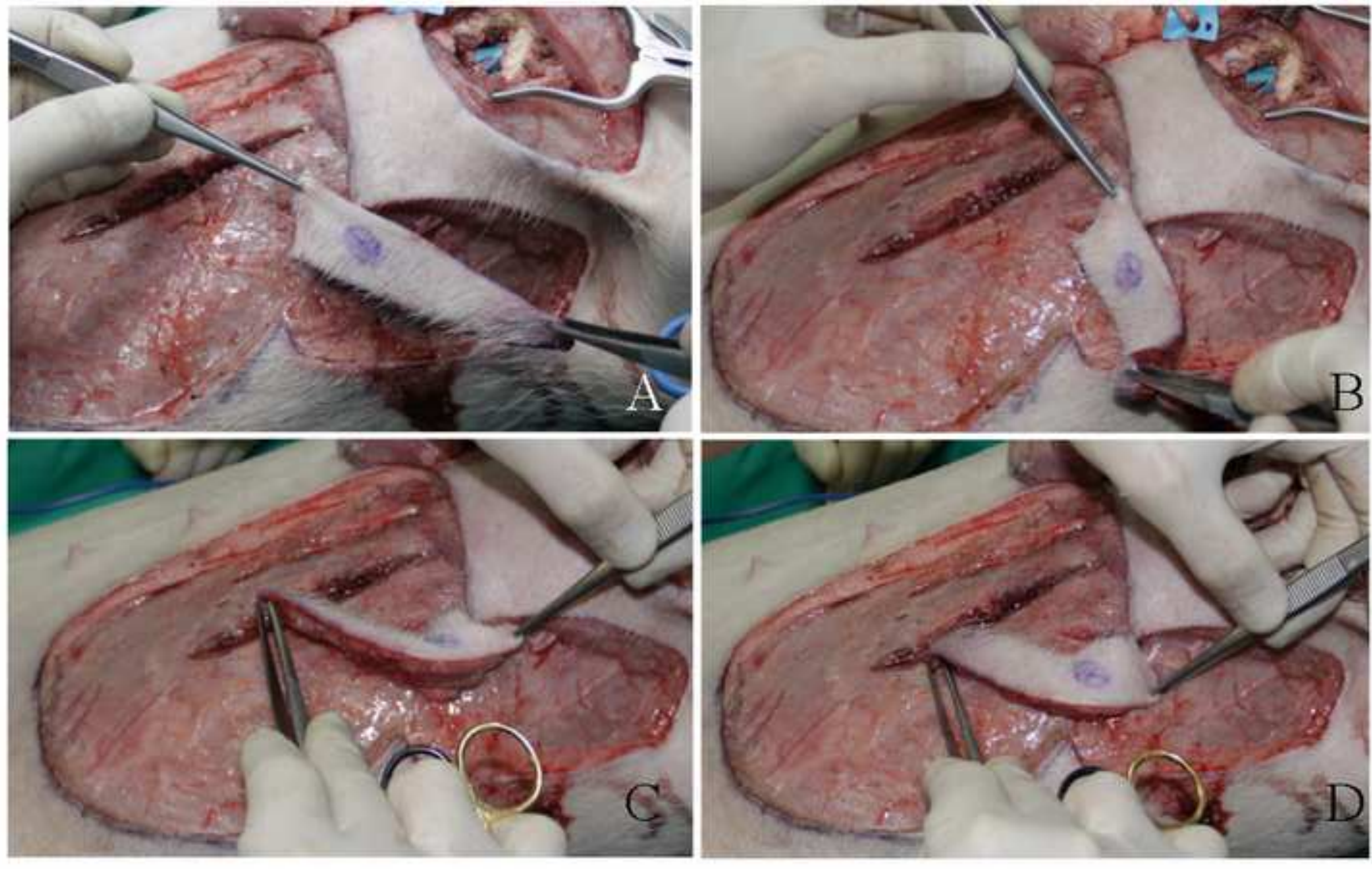




\section{Acknowledgements}

Marta Cajozzo, Tiziana Roggio, Nicolò Favuzza, Nicola Zingaretti, Andrea Monticelli, Sandro Rizzato, Giulia Boscaini 


\section{Declaration of Interest form}

None of the authors has any conflict of interest to declare

\section{Submission declaration and verification}

The work described has not been published previously, it is not under consideration for publication elsewhere, its publication is approved by all authors and tacitly or explicitly by the responsible authorities where the work was carried out,

and, if accepted, it will not be published elsewhere in the same form, in English or in any other language, including electronically without the written consent of the copyrightholder. 